Marquette University

\title{
e-Publications@Marquette
}

College of Nursing Faculty Research and

Publications

Nursing, College of

$12-2020$

\section{Adaptation of the Parent Readiness for Hospital Discharge Scale with Mothers of Preterm Infants Discharged from the Neonatal Intensive Care Unit}

\author{
Naiire Salmani \\ Shahid Sadoughi University of Medical Sciences \\ Marzieh Zare Marvast \\ Shahid Sadoughi University of Medical Sciences \\ Somayeh Kahdouei \\ Imam Javad University \\ Marianne E. Weiss \\ Marquette University, marianne.weiss@marquette.edu
}

Follow this and additional works at: https://epublications.marquette.edu/nursing_fac

Part of the Nursing Commons

\section{Recommended Citation}

Salmani, Naiire; Marvast, Marzieh Zare; Kahdouei, Somayeh; and Weiss, Marianne E., "Adaptation of the Parent Readiness for Hospital Discharge Scale with Mothers of Preterm Infants Discharged from the Neonatal Intensive Care Unit" (2020). College of Nursing Faculty Research and Publications. 811.

https://epublications.marquette.edu/nursing_fac/811 
Marquette University

e-Publications@Marquette

\section{Nursing Faculty Research and Publications/College of Nursing}

This paper is NOT THE PUBLISHED VERSION; but the author's final, peer-reviewed manuscript. The published version may be accessed by following the link in the citation below.

Journal of Clinical Nursing, Vol. 29, No. 23-24 (September 4, 2020): 4544-4553. DOI. This article is (C) Wiley and permission has been granted for this version to appear in e-Publications@Marquette. Wiley does not grant permission for this article to be further copied/distributed or hosted elsewhere without the express permission from Wiley.

\section{Adaptation of The Parent Readiness for Hospital Discharge Scale with Mothers of Preterm Infants Discharged from The Neonatal Intensive Care Unit}

\section{Naiire Salmani}

School of Nursing and Midwifery, Shahid Sadoughi University of Medical Sciences, Yazd, Iran Marzieh Zare Marvast

School of Nursing and Midwifery, Shahid Sadoughi University of Medical Sciences, Yazd, Iran Somayeh Kahdouei

Faculty of Psychology, Imam Javad University, Yazd, Iran

Marianne E. Weiss

College of Nursing, Marquette University, Milwaukee, WI 


\section{Abstract}

Aims and objectives

To evaluate the psychometric properties of a new Persian translation of the Readiness for Hospital Discharge Scale.

\section{Background}

Globally, one in 10 newborns are born preterm and many require care in a neonatal intensive care unit (NICU). A primary role of NICU nurses is to assure parents are well prepared to take their newborns home from the hospital. Assessment of parent perception of discharge readiness provides important input into discharge decisions. The availability of reliable and valid instruments tested within the geographical and cultural context is needed for a comprehensive assessment of predischarge readiness, so that parent needs can be identified and the necessary interventions designed and implemented.

\section{Design}

This psychometrics study included a convenience sample of 200 mothers with preterm infants being discharged from the NICU of Shahid Sadoughi Hospital in Yazd, Iran. The original 29-item version of the Readiness for Hospital Discharge Scale-Parent questionnaire was translated into Persian using the standard forward-backward method. Face, content and construct validity (principal components analysis), and reliability (internal consistency-Cronbach's alpha) were assessed. Methods followed STROBE criteria as applicable (see Appendix S1).

\section{Results}

The content validity index and content validity ratio were both 0.93 . Construct validity testing identified 6 factors (mother and infant physical-psychological readiness, expected support, knowledge of future events and care, knowledge of infant personal care, pain and therapeutic interventions). Using Cronbach's alpha coefficient, the reliability of the whole instrument was estimated to be 0.87 .

\section{Conclusion}

The Persian Readiness for Hospital Discharge-Parental Form for use with mothers of preterm infants being discharged from an Iranian NICU has acceptable validity and reliability.

\section{Relevance to Practice}

This tool can be used before discharge to determine the needs of mothers and design the necessary measures to improve quality of discharge care.

What does this paper contribute to the wider global clinical community?

- $\quad$ Findings suggest that the Persian version of the Parent Readiness for Hospital Discharge Scale has a high level of reliability as well as acceptable content and construct validity, and is helpful and easy to use for comprehensive assessment of predischarge readiness.

- The Readiness for Hospital Discharge Scale can be used easily by care team members before discharge of preterm infants from neonatal intensive care units to plan interventions in accordance with the needs of mothers in the Iranian cultural context. 
- $\quad$ By using this tool, nurses can identify shortcomings in preparation for discharge before mothers and their preterm infants leave the hospital.

\section{INTRODUCTION}

According to the World Health Organization (WHO), every year one in 10 infants is born preterm (gestational age below 37 weeks) (WHO, 2016). In the USA, approximately $11.7 \%$ of all live births are preterm infants (Hamilton, Hoyert, Martin, Strobino, \& Guyer, 2013). The rate of preterm birth has increased over the past two decades (Sharifi et al., 2018), creating one of the most important global health challenges. The rise in preterm births places a strain on health systems by increasing admissions to the neonatal intensive care unit (NICU) (Burnham, feeley, \& Sherrard, 2013).

Preterm infants are more susceptible to various health issues than term infants (Kelly, 2006). They are hospitalised in the NICU for days, weeks or months to survive (Ong, Preece, Emmett, Ahmed, \& Dunger, 2002). Scientific advances and technological improvements in neonatal intensive care have increasingly improved the survival of preterm infants (te Pas, 2017). Having a high-risk infant in the NICU environment can cause parental anxiety and depression and experiencing such feelings impedes learning about the parental role in taking care of the infant (Singer et al., 2010). Preparing parents to take their baby home from the hospital is a core function of NICU nursing care. Knowing parents' perceptions of their readiness for discharge can provide the nurse with valuable information on which to base anticipatory interventions to better prepare parents for the transition to home and management of the infant's care needs at home (Weiss et al., 2008). Valid and reliable tools are needed in clinical practice settings for consistent and thorough assessment of parental readiness for discharge of their infant from the NICU. Prior to use across diverse patient groups, tools with established psychometric properties need adaptation and testing in new cultural contexts before implementation and integration within clinical practice protocols.

\section{BACKGROUND}

The NICU ward is an environment full of state-of-the-art technology that limits parental interactions with infants and often prevents parents from being the primary caregiver to their infants. Ultimately, as a result of experiencing such conditions, discharge from the NICU can be a stressful experience for parents who may feel unprepared for the transition to managing their newborns' care at home (Burnham et al., 2013). Initiatives to discharge infants from the NICU as soon as possible to reduce hospital costs (Richardson et al., 2001), make effective use of hospital beds, prevent nosocomial infections and shorten the separation of parent and infant (Lian, Ying, Peng, \& Yann, 2008) can have unintended consequences. Infant health problems may not be sufficiently resolved, and parents may not have enough time to acquire the knowledge and skills needed to care for the newborn at home. Hospitalised infants pose unique challenges to parental readiness for discharge because these infants have complex medical conditions and special needs (Lamarche-Vadel et al., 2004). Since parents are primary caregivers of preterm neonates after discharge, it is important that parents' readiness be assessed before transferring the infant from hospital to home to ensure infant safety and improve postdischarge care outcomes (Chen \& Bai, 2017). Parent lack of readiness for the infant's discharge can create anxiety, doubts about the competence of managing infant care (Suderman, Deatrich, Johnson, \& 
Sawatzky-Dickson, 2000), loss of self-confidence, low confidence in infant care, and difficulty in adapting to new circumstances and solving family-related challenges (Weiss \& Lokken, 2009).

As discharge nears, many parents express their fear and lack of self-confidence about the infant's condition by saying "My baby is too fragile" as they anticipate going home with medical equipment and medicines, and with needs for recurring specialist visits (Discenza, 2009). Experiencing unpreparedness can have long-term consequences for the parent and child, including disruption in the infant's development, disruptive mother-infant relationships, negative interactions with parents, prolonged maternal stress and long-term effects on infant behaviour (Hynan, Mounts, \& Vanderbilt, 2013).

Both parent and infant factors need to be addressed in order to discharge the infant from the NICU. In addition to the physiological indicators associated with the infant, parents must have the ability, confidence and willingness for discharge as signs of readiness for discharge (Bissell \& Long, 2003) The American Academy of Pediatrics' (AAP) recommendations for decision-making about discharge of highrisk infants includes determination of infant physiological and developmental readiness, family and home environmental readiness (including parental knowledge and caregiving abilities, resource availability and home physical facilities), and community and healthcare system readiness (including primary care, specialty care and home nursing follow-up visits as needed) (AAP Committee on Fetus \& Newborn, 2008).

Formalising a discharge readiness assessment can help identify at-risk families who are likely to experience adverse outcomes, such as readmission or repeated use of emergency services, due to lack of readiness to discharge (Raines, 2013b). Parent assessment before infant discharge would provide comprehensive insight into promoting a successful transition from hospital to home care and improving postdischarge outcomes (Chen \& Bai, 2017; Weiss et al., 2017). Preparation for discharge is a multifaceted effort in which nurses have the primary responsibility for preparing parents for discharge through educational interventions to prepare family members with the knowledge and skills needed to successfully transition the infant's care from hospital to home (Griffin \& Pickler, 2011).

Assessing the parent's readiness for their infant's discharge requires a reliable tool that provides a comprehensive assessment of parental readiness prior to infant discharge, so that the parent's needs can be identified prior to discharge and necessary anticipatory interventions can be designed and implemented accordingly (Weiss et al., 2008). The Readiness for Hospital Discharge Scale (RHDS) is administered on the day of hospital discharge normally within $4 \mathrm{hr}$ prior to discharge (Weiss \& Piacentine, 2006; Weiss et al., 2017). Other available tools for assessing discharge readiness are administered retrospectively from 1-12 weeks after hospital discharge (Coleman, Mahoney, \& Parry, 2005; Desai et al.., 2018; Graumlich, Novotny, \& Aldag, 2008), providing outcome measures of the discharge transition from hospital to home but precluding their use as clinical tools for assessment during discharge preparation. The RHDS has been tested in multiple studies in the USA and internationally with adult patients, parents of hospitalised children and postpartum mothers. The parent form of the RHDS, completed with parents of hospitalised children including NICU parents, has demonstrated acceptable reliability and construct validity in studies of American parents (Weiss et al., 2008). This instrument has also undergone psychometric testing in China to assess parents' readiness for preterm infants' discharge from the NICU. The emerging factor structure was similar for 3 of the subscales (knowledge, expected support, physical and emotional status); however, the coping 
subscale from the original US scale was eliminated as it did not perform adequately in the confirmatory factor analysis; the authors describe limited parental visitation prior to discharge that can result in parents not adequately understanding the challenges facing them at home following discharge (Chen \& Bai, 2017).

Focusing on the fact that no valid instrument is available in Iran to assess discharge readiness of mothers with neonates admitted to the NICU, and considering the importance of parental readiness for discharge of preterm infants from NICU, the present study aimed to determine the psychometric properties of "RHDS- parent form" in mothers with preterm infants being discharged from the NICU of Shahid Sadoughi Hospital in Yazd, Iran.

\section{METHODS}

\subsection{Design and sample}

This study is a psychometric evaluation conducted in 2019. STROBE criteria were reviewed and used as applicable. The study used a convenience sample of mothers with preterm infants who were discharged from the NICU of Shahid Sadoughi Hospital in Yazd, Iran. Inclusion criteria for women participating in the study were as follows: mother of preterm infant with gestational age of 2436 weeks, at least 18 years old, primary caregiver during infants' hospitalisation in the NICU, fluent in Persian, and able to read the consent document and respond to questions on the RHDS. Infants had a physician order to discharge, and their mothers were returning home directly accompanied by the infant. Mothers' exclusion criteria were psychological problems resulting in inability to concentrate and answer the questions and drug addiction.

\subsection{Measure}

The original parent form of the RHDS had 29 items in 5 domains including parent personal status, child personal status, knowledge, perceived coping ability and expected support (Weiss et al., 2008). Item 1 of the scale is a dichotomous yes/no item about parental readiness that is not included in scale calculations. Items in the scale are numbered 2 through 24 , with letters $a$ and $b$ to differentiate parallel parent and child items (see Table 2 ). The RHDS is scored on a 0 to 10 rating scale with higher ratings indicating parent perception of greater readiness. Items 4 a \& b related to pain and $6 a$ related to stress are reverse scored. In initial testing, the Cronbach's alpha reliability estimate was 0.85 (Weiss et al., 2008; and 0.89 and 0.88 in subsequent studies (Weiss, Lerret, Sawin, \& Schiffman, 2020; Weiss et al., 2017).

Construct validity was established with a combined sample of parents of hospitalised children, adult medical-surgical patients and postpartum mothers (Weiss \& Piacentine, 2006). Subsequently, evidence of predictive validity for paediatric patients of both the full form and a shorter 8 item form of the scale has been reported; lower scale scores are associated with greater postdischarge coping difficulty and higher odds of readmission within 30 days after discharge (Weiss et al., 2020).

The method of translation and psychometric evaluation of this instrument followed methods recommended by the Beaton, Bombardier, Guillemin, and Ferraz (2000). With permission from the instrument developer (M.W.), the instrument was initially translated from English into Persian by two independent translators simultaneously. The translators tried to translate the words accurately within 
the context of the Persian culture. In the second step, the translations were compared and reconciled into a single translation. The translations were then compared and the discrepancies were identified and corrected based on additional experts' opinions. In the third step, the Persian version was given to two translators (other than the former translators) whose native language was English to translate from Persian into English. After receiving the translations, checking of translations by experts, correcting discrepancies and integrating the translations, the prepared final translation was emailed to the instrument developer to verify the conformity of the submitted version with the original one. After receiving the instrument developer's comments and endorsement of the translation, the final Persian version entered the psychometric testing process for face validity, content validity, construct validity and instrument reliability.

\subsection{Psychometric analysis}

Face validity was checked with a sample of 10 mothers with preterm infants being discharged from the NICU who provided comments about any difficulties in comprehending the words and expressions, suitability and desirable relevance of the items, and the possibility of ambiguity and incomplete perceptions of expressions or failure of meanings. Additionally, expert reviewers (10 faculty members and paediatricians) evaluated the desirability of the expressions in terms of clarity (using simple and understandable words) and use of common language (avoiding technical terms). These reviewers were asked to provide comments and suggestions related to understanding, difficulty level of expressions and the ambiguity of each item. After receiving feedback, the necessary corrections were made.

To assess content validity, both quantitative and qualitative methods were used. In the qualitative evaluation of content validity, the instrument was given to experts ( 5 members of Yazd Shahid Sadoughi Faculty of Nursing and 5 neonatal specialists at Shahid Sadoughi Hospital), and their comments were received. To check the content validity in a quantitative way, content validity ratio and content validity index were evaluated. To check the content validity ratio, experts were asked to rate each phrase on a three-point Likert scale "necessary, useful but not necessary and not necessary." The content validity ratio is calculated based on the proportion of expert rating the items as necessary. Based on the Lawshe table, for the number of experts $(n=10)$, the minimum acceptable numerical value would be 0.62 (Mohammadbeigi, Mohammadsalehi, \& Aligol, 2015).

To check the content validity index, we used the Item and Scale Average method as described in Polit and Beck (2006). The experts were asked to rate the relevance, clarity and simplicity of the items on a 4-point Likert scale. According to Polit, Beck, and Owen (2007), the acceptable value for the content validity index of the items and the content validity index of the scale with 10 experts is 0.90 and above.

To evaluate construct validity, principal component analysis (PCA) with varimax rotation was used to examine the internal relationships between variables to discover the classes of variables that are most closely related to each other. Thus, those items in the instrument that show the highest correlation with each factor can be used as items within each factor or component of the instrument (Williams, Onsman, \& Brown, 2010). PCA was selected as the analytic method because of the non-normal distribution of the data, with scores skewed towards positive responses.

To determine the reliability of the instrument, internal consistency was assessed using the Cronbach's alpha coefficient. Data analysis was performed using SPSS version 18 software. 


\subsection{Sample size}

The number of subjects recommended for factor analysis is 5-10 per item in the scale (Knapp \& Brown, 1995) or at least 200 subjects (MacCallum \& Austin, 2000). Therefore, 200 mothers meeting the inclusion criteria were included in the study.

\subsection{Data collection}

Data collection began after receiving Ethics Code approval from the Vice Chancellor for Research of Shahid Sadoughi University of Medical Sciences, Yazd. The researcher introduced herself to mothers during a visit to the NICU of Shahid Sadoughi Hospital, outlined the aims of the study and explained the procedure. After obtaining the written consent, the researcher requested that the mothers complete a demographic questionnaire and the parent RHDS on the day of hospital discharge prior to leaving the hospital.

\section{RESULTS}

Mean age of mothers was $28.28 \pm 6.03$ years; the mean age of infants was $33.65 \pm 2.56$ weeks gestation. The mean number of days of infant hospitalisation in NICU was $11.75 \pm 15.08,50 \%$ of the infants were female, $88 \%$ of mothers were housewives, $43 \%$ of mothers had high school diploma, $69 \%$ of mothers had a caesarean birth, and $45.5 \%$ of mothers were primiparas (first birth) (Table 1).

Table 1. Frequency distribution of demographic variables $(n=200)$

\begin{tabular}{|c|l|l|}
\hline Variable & Absolute frequency & Relative frequency \\
\hline Infant's sex & & \\
\hline Female & 100 & $50 \%$ \\
\hline Male & 100 & $50 \%$ \\
\hline Native Iranian & & \\
\hline Yes & 132 & $66 \%$ \\
\hline No & 68 & $34 \%$ \\
\hline Level of Education & & \\
\hline High school & 44 & $22 \%$ \\
\hline Diploma & 86 & $43 \%$ \\
\hline Bachelor & 63 & $31.5 \%$ \\
\hline Masters & 7 & $3.5 \%$ \\
\hline Job & & \\
\hline Housewife & 176 & $88 \%$ \\
\hline Employee & 24 & $12 \%$ \\
\hline Parity & & \\
\hline 1 & 91 & $45.5 \%$ \\
\hline 2 & 68 & $34 \%$ \\
\hline 3 & 35 & $17.5 \%$ \\
\hline 4 & 6 & $3 \%$ \\
\hline Type of birth & & $69 \%$ \\
\hline Cesarean & 138 & $31 \%$ \\
\hline Vaginal & 62 & \\
\hline & & \\
\hline & & \\
\hline & & \\
\hline & & \\
\hline
\end{tabular}




\subsection{Face and content validity}

From the patients and specialists' comments, items needing corrections were reviewed and minor revisions to improve clarity in wording and meaning were made. Quantitatively, content validity based on expert review revealed a content validity index of the instrument was 0.93 and a content validity ratio 0.93 . Thus, the content validity of the tool was confirmed.

\subsection{Construct validity}

PCA was performed on data from 200 mothers. The results of the Kaiser-Meyer-Olkin (KMO) measure indicated the adequacy of sampling for using factor analysis. (KMO $=0.893$ ) and Bartlett's Spearman's test with chi-Square $=3859 / 394$ and $p<.001$ indicated adequacy of the dataset for performing factoring. The results of PCA showed that six factors with an eigenvalue greater than 1 accounted for $68.05 \%$ of scale variance. As it is shown in Table $\mathbf{2}$, Factor 1 entitled "mother and infant physicalpsychological readiness" included 10 items; Factor 2 entitled "expected support" included five items; Factor 3 entitled "knowledge of future events and care" included five items; Factor 4 entitled "infant personal care knowledge" included four items; Factor 5 entitled "pain" included two items; Factor 6 entitled "treatment interventions" included three items.

Table 2. Rotated Component Matrix

\begin{tabular}{|l|l|l|l|l|l|l|}
\hline Items & $\begin{array}{l}\text { Factor } \\
\mathbf{1}\end{array}$ & $\begin{array}{l}\text { Factor } \\
\mathbf{2}\end{array}$ & $\begin{array}{l}\text { Factor } \\
\mathbf{3}\end{array}$ & $\begin{array}{l}\text { Factor } \\
\mathbf{4}\end{array}$ & $\begin{array}{l}\text { Factor } \\
\mathbf{5}\end{array}$ & $\begin{array}{l}\text { Factor } \\
\mathbf{6}\end{array}$ \\
\hline 2a. parent physically ready & 0.425 & & & & & \\
\hline 2b. child physically ready & 0.626 & & & & & \\
\hline 4a. parent strength & 0.600 & & & & & \\
\hline 4b. child strength & 0.737 & & & & & \\
\hline 5a. parent energy & 0.680 & & & & & \\
\hline 5b. child energy & 0.787 & & & & & \\
\hline 6a. parent stress & 0.520 & & & & & \\
\hline 7a. parent emotionally ready & 0.448 & & & & & \\
\hline $\begin{array}{l}\text { 8a. parent physical ability to care for } \\
\text { yourself }\end{array}$ & 0.744 & & & & & \\
\hline 8b. child - usual activities for age & 0.596 & & & & & \\
\hline 18. handle the demands of life at home? & & 0.482 & & & & \\
\hline 21. emotional support & & 0.759 & & & & \\
\hline 22. help with child's personal care & & 0.850 & & & & \\
\hline 23. help with household activities & & 0.749 & & & & \\
\hline 24. help child's medical care & & 0.803 & & & & \\
\hline 13. problems to watch for & & & 0.670 & & & \\
\hline 14. who and when to call for problems & & & 0.765 & & & \\
\hline 15. allowed and not allowed to do & & & 0.786 & & & \\
\hline 16. what happens next & & & 0.753 & & & \\
\hline $\begin{array}{l}\text { 17. services and information in your } \\
\text { community }\end{array}$ & & & 0.737 & & & \\
\hline 9. caring for child & & & & 0.503 & & \\
\hline 10. personal needs & & & & 0.582 & & \\
\hline
\end{tabular}




\begin{tabular}{|l|l|l|l|l|l|l|}
\hline 11. growth and development & & & & 0.497 & & \\
\hline 19. perform child's personal care & & & & 0.535 & & \\
\hline 3a. pain or discomfort & & & & & 0.755 & \\
\hline 3b. pain or discomfort & & & & & 0.497 & \\
\hline 12. medical needs & & & & & & 0.523 \\
\hline 20. perform child's medical treatments & & & & & & 0.579 \\
\hline 7b. child emotions and/or behaviour & & & & & & 0.797 \\
\hline
\end{tabular}

Note: The original and translated scales and permission to use can be obtained

at: https://www.marquette.edu/nursing/hospital-discharge-scales-general.php.

The estimates of internal consistency of the parent RHDS (Cronbach's alpha coefficient), and mean scores and standard deviations for items, subscales and total scale are presented in Table 3 . The total scale alpha and 3 of 6 domains exceeded $0.80,2$ subscales exceeded 0.70 , and one scale achieved an alpha of 0.70 after deleting one item (item 7B). Items with the lowest items scores were parent stress and emotional readiness in the "physical-psychological readiness" domain, items in the "knowledge of future events and care" and "treatment interventions" domains, and the "pain domain." These items point to opportunities to improve preparation for discharge through education, counselling and pain interventions.

Table 3. Item and scale statistics

\begin{tabular}{|l|l|l|l|l|}
\hline Items & Mean (SD) & $\begin{array}{l}\text { Item-to- } \\
\text { subscale } \\
\text { correlation }\end{array}$ & $\begin{array}{l}\text { Alpha if } \\
\text { item } \\
\text { deleted }\end{array}$ & $\begin{array}{l}\text { Cronbach's } \\
\text { alpha }\end{array}$ \\
\hline $\begin{array}{l}\text { Factor 1: Mother and infant physical- } \\
\text { psychological readiness }\end{array}$ & & & & \\
\hline 2a. parent physically ready & $8.46(1.31)$ & 0.64 & 0.66 & 0.72 \\
\hline 2b. child physically ready & $8.28(1.28)$ & 0.65 & 0.66 & \\
\hline 4a. parent strength & $8.29(1.10)$ & 0.70 & 0.66 & \\
\hline 4b. child strength & $8.06(1.26)$ & 0.70 & 0.65 & \\
\hline 5a. parent energy & $8.10(1.40)$ & 0.70 & 0.65 & \\
\hline 5b. child energy & $8.00(1.42)$ & 0.70 & 0.64 & \\
\hline 6a. parent stress & $6.09(2.43)$ & 0.58 & 0.90 & \\
\hline 7a. parent emotionally ready & $7.71(1.70)$ & 0.51 & 0.68 & \\
\hline 8a. parent physical ability to care for yourself & $8.65(1.18)$ & 0.47 & 0.69 & \\
\hline 8b. child - usual activities for age & $7.55(1.53)$ & 0.60 & 0.66 & \\
\hline Factor 2: Expected Support & & & & \\
\hline 18. handle the demands of life at home? & $8.32(1.28)$ & 0.59 & 0.90 & 0.89 \\
\hline 21. emotional support & $8.58(1.52)$ & 0.78 & 0.86 & \\
\hline 22. help with child's personal care & $8.55(1.60)$ & 0.82 & 0.85 & \\
\hline 23. help with household activities & $8.12(1.72)$ & 0.72 & 0.87 & \\
\hline 24. help child's medical care & $8.66(1.50)$ & 0.78 & 0.86 & \\
\hline Factor 3: Knowledge of future events and care & & & & \\
\hline 13. problems to watch for & $7.13(1.66)$ & 0.64 & 0.83 & 0.85 \\
\hline 14. who and when to call for problems & $7.54(1.91)$ & 0.64 & 0.83 & \\
\hline 15. allowed and not allowed to do & $6.78(1.77)$ & 0.71 & 0.81 & \\
\hline
\end{tabular}




\begin{tabular}{|l|l|l|l|l|}
\hline 16. what happens next & $6.55(1.78)$ & 0.68 & 0.82 & \\
\hline $\begin{array}{l}\text { 17. services and information in your } \\
\text { community }\end{array}$ & $7.41(1.46)$ & 0.67 & 0.82 & \\
\hline Factor 4: Infant personal care knowledge & & & & \\
\hline 9. caring for child & $8.26(1.27)$ & 0.61 & 0.76 & 0.80 \\
\hline 10. personal needs & $8.44(1.16)$ & 0.67 & 0.73 & \\
\hline 11. growth and development & $8.03(1.44)$ & 0.62 & 0.76 & \\
\hline 19. perform child's personal care & $8.73(1.10)$ & 0.60 & 0.77 & \\
\hline Factor 5: Pain & & & & \\
\hline 3a. parent pain or discomfort & $6.68(2.30)$ & 0.57 & 0 & 0.71 \\
\hline 3b. child pain or discomfort & $7.75(1.73)$ & 0.57 & 0 & \\
\hline Factor 6: Treatment interventions & & & & \\
\hline 12. medical needs & $7.70(1.46)$ & 0.49 & 0.40 & 0.60 \\
\hline 20. perform child's medical treatments & $7.96(1.47)$ & 0.47 & 0.43 & \\
\hline 7b. child emotions and/or behaviour ${ }^{a}$ & $6.90(2.07)$ & 0.32 & 0.70 & \\
\hline
\end{tabular}

a Item deleted: item $7 b$.

\section{DISCUSSION}

The present study is the first psychometric report of the newly translated Persian version of the "RHDS-parent form" with mothers with preterm infants admitted to the NICU. Findings indicated that the "RHDS- parent form" had acceptable reliability and content validity consistent with prior testing in other countries (Chen \& Bai, 2017; Weiss et al., 2008, 2020). Construct validity testing revealed both similarities and differences to findings from testing in an American sample.

Content validity analysis revealed high index and ratio scores (both $=0.93$ ), which suggested that no items needed to be deleted at this stage. These findings are higher than previously reported in the original development of the form, where the content validity index was assessed and reported to be 0.76 (Weiss et al., 2008). In the psychometric evaluation of the Chinese translation of the scale, readability and comprehensibility were evaluated and items revised during pilot testing; however, specific results were not reported. Convergent validity was also assessed for the Chinese translation but was not assessed in this study of Iranian parents. Quality of patient education about discharge was strongly associated with parental readiness for discharge from the NICU. The better the quality of parent teaching about discharge and the transition home, the better the readiness for discharge (Chen \& Bai, 2017). This finding emphasises the importance of what and how nurses teach parents before discharge in achieving positive parent perceptions of their readiness to take the infant home.

Results of the analysis of the factor structure of the Parent RHDS with our sample of Iranian NICU parents had both similarities and differences to the studies in the USA with parents of hospitalised children aged 0-17 (Weiss et al., 2020) and in China with parents of preterm infants discharged from the NICU (Chen \& Bai, 2017). Our Iranian study resulted in a 6-factor structure using all of the original 29 items. The factor domains were as follows: mother and infant physical-psychological readiness, expected support, knowledge of future events and care, infant personal care knowledge, pain and treatment interventions. The Chinese study resulted in a 4-factor structure (knowledge, expected support, physical-emotional state and pain domains), with 22 items (Chen \& Bai, 2017). In a recent US 
study that combined data from 4 studies specifically for the purposes of psychometric evaluation, the 5 domains using 23 items of the original scale were retained (expected support, perceived coping ability, knowledge, parent personal status and child personal status) (Weiss et al., 2020). Scale factors reflecting maternal-infant physical-emotional status, knowledge and expected support emerged as common dimensions of discharge readiness across the 3 cultural contexts. Pain was a factor in common in results from the Chinese and Persian which included exclusively NICU parents. Coping ability as a distinct factor was unique to the US sample.

In the present study, the first identified domain was "mother and infant physical-psychological readiness"; this domain included all items related to maternal and infant physical status as well as maternal mental status. Similarly, Chen and Bai (2017) reported a 7 item a physical-emotional state domain with 7 items, all of which are in common with our physical-psychological readiness domain (Chen \& Bai, 2017). The Iranian and Chinese versions of the scale combine two domains described separately as the personal status of the parent and the personal status of the child in the original US version of the scale (Weiss et al., 2008). In subsequent revisions, items related to "energy today" were removed due to their high correlation with items related to "strength today." Another item was also removed (difficulty in managing child's emotions and behaviours) due to cross-loading on multiple factors (Weiss et al., 2020). This item may not be as relevant in the NICU parent population as the broader paediatric population.

The findings of convergence of items related to physical and emotional experience indicate that along with physical health, mental health is extremely important for mothers of preterm infants discharged from NICUs. Experiencing the stress associated with having a preterm infant in the NICU can be a factor in weakening physical ability (Epel, McEwen, \& Ickovics, 1998). It also interferes with learning, memory, cognitive abilities and the ability to perform expected actions (Mackenzie, Smith, Hasher, Leach, \& Behl, 2007). NICU mothers frequently feel a deep sadness and as they project into the future, they think about taking care of the preterm infant alone at home, while so far a care team has had such responsibility (Raines, 2013a). The findings of our study support a holistic view of physical and emotional readiness for discharge of the mother-infant dyad.

The second domain is the "expected support" domain, which is similar to Chinese and American studies (Chen \& Bai, 2017; Weiss et al., 2020). Parent perceptions of support after discharge are a key element of overall perceptions of readiness to go home with a high-risk newborn. Having support at home can facilitate the transition from hospital to home. The contacts parents make with friends and relatives after discharge show the importance of support that family members can provide to meet the needs of parents (Anthony \& Hudson-Barr, 2004). The questions in the RHDS instrument do not specify the relative importance of spouse, maternal grandmother or other significant support persons, only whether the mother perceives that she will have adequate help. The importance of different sources of support may be different across cultures; research is needed to inform healthcare professionals about inclusion of support persons in preparatory care for discharge.

Three domains relate to the knowledge and skills needed by mothers of infants discharged from the NICU, specifically are "knowledge of future events and care," "knowledge of infant personal care" and "treatment interventions." These domains are combined in a single knowledge domain in the Chinese and American studies (Chen \& Bai, 2017; Weiss et al., 2008, 2017). Differences in the study populations 
may account for this difference. Chen and Bai (2017) reported that according to Chinese hospital policies parents were not permitted to be present in NICUs. They only received reports about their infant through the doctor 2-3 times a week, and parents had no opportunity to provide personal care for their infant. This lack of interaction with the infant to meet the needs and to take care of the infant can lead parents to be unaware of the challenges and issues that they may face at home. In addition, most of the samples in the Chinese study were fathers of preterm infants and most mothers were not present at the time of discharge because they had not completed their period of confinement after childbirth. The explanation is also relevant to the "treatment interventions" domain, which emerged as a separate domain in the Persian version of the RHDS about specific knowledge and skills related to medical care and treatment, but not in prior studies (Chen \& Bai, 2017; Weiss et al., 2020). Fathers in the Chinese study may not have been aware of the needs and therapeutic interventions of preterm infants. Similarly, in the studies by Weiss et al., (2008), Weiss et al., (2020), the heterogeneity of the study participants including parents with children from newborn to 18 years with various medical and surgical problems played a role in determining the domains.

The domain of "infant personal care knowledge" in the new Persian form of the scale assesses maternal readiness for discharge from infant care knowledge and skills perspective. Parents with preterm infants being discharged from the NICU have specific educational needs in several domains including breastfeeding, formula feeding, skincare, umbilical cord care and sleeping status (AAP Committee on Fetus and Newborn, 2008). Since infants discharged from intensive care units may need home medical equipment, their mothers must have relevant knowledge about how to manage various equipment including monitoring devices, oxygen therapy and drug therapy equipment (AAP Committee on Injury \& Prevention, 2011; Bull \& Engle, 2009). They also need to know what to do and where to go when conditions related to the baby's clinical situation occur (Scherf \& Reid, 2006). Mothers must also acquire knowledge of the predictable process of infant growth and development during the first few weeks after discharge (Smith, Hwang, Dukhovny, Young, \& Pursley, 2013). Therefore, education provided by nurses with specialty training in neonatal intensive care is needed to be most effective in answering mothers' questions and concerns (Bruder \& Cole, 1991).

Mothers of newborns discharged from the NICU also need to have the relevant knowledge to know how to manage future events and imminent conditions such as infant resuscitation, accessible centres and competent authorities available in an emergency (Scherf \& Reid, 2006). They should also know that they are responsible for following up on screening tests. Insufficient knowledge in this domain can lead to decreased acceptance of screening tests such as hearing, visual and brain health assessment (Arzani, Kermanshahi, Zahedpasha, \& SalehMohamadzadeh, 2009). Therefore, knowledge of subsequent follow-up is important to provide important care needed for preterm infants (Zarbock, 1998).

The finding of a separate "pain" domain is similar to the study by Chen \& Bai, 2017, though it is not a separate domain in the US study (Weiss et al., 2020). Studies show that parents with preterm infants admitted to the NICU worry about their infant's pain (Franck et al., 2011). One of the stressful experiences for mothers is to see their baby in pain (Brunssen \& Miles, 1996). The mother's inability to support the baby in pain can continue to be a source of stress even after the discharge (Wereszczak, Miles, \& Holditch-Davis, 1997). The presence of pain can be considered as the main symptom of a 
disease and can cause the parent to feel uncertain about taking care of her baby, especially when the parent does not feel at ease. Mothers with infants in the NICU are themselves postpartum, experiencing varying levels of pain associated with both vaginal and caesarean birth that may interfere with their ability and attention to their infants' needs (Declercq, Cunningham, Johnson, \& Sakala, 2008). Therefore, pain assessment in the parent or infant is a priority at discharge (Chen \& Bai, 2017). Educating mothers about infant pain and ways to relieve it in the postdischarge phase can help mothers play a more active role in pain management (Franck et al., 2011).

Reliability of the parent form of the RHDS has been consistently adequate in US (Weiss

et al., 2008, 2020, 2017) and Chinese (Chen \& Bai, 2017) studies, as it was in this study. The reliability and similarities in the content and construct validity of the scale across populations point to the universality of the concept of discharge readiness and the importance as a clinical indicator of parent status prior to leaving the hospital with an infant following NICU hospitalisation.

\section{LIMITATIONS}

This study had several limitations. First, in this study, the convenience sample included mothers of newborns admitted to a NICU of a single university hospital in a city in Iran. Further studies are needed with mothers with neonates hospitalised in different hospitals in different geographic regions of Iran. A better understanding of parental readiness for discharge could be achieved by collecting data in further studies from fathers or others who serve as the support persons for mothers after hospital discharge. The second limitation of the sample was the language. Persian-speaking mothers who were able to communicate were included in the study but mothers from the south-western part of Iran who spoke and read other local dialects and were not fluent in Persian were excluded because they were unable to understand the researcher's speech and the instrument. Therefore, psychometric evaluation of the tool in different demographic and socioeconomic conditions could contribute to its general validation. The third limitation was the lack of psychometric instruments to be used to determine the

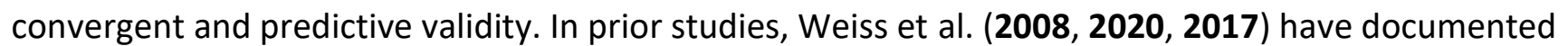
influence of the quality of discharge teaching by nurses on parent readiness for discharge, and the association of low readiness for discharge with greater difficulty in coping at home after discharge. The tools measuring these constructs (Quality of Discharge Teaching Scale, Post-Discharge Coping Difficulty Scale) could be used for further validation of the Persian version of the Parent RHDS.

\section{CONCLUSION}

The results of the study showed that the Parent Readiness for Hospital Discharge Scale is a reliable and valid 28-item instrument for assessing the readiness of Persian-speaking mothers of infants being discharged from an Iranian NICU. With 6 domains, this instrument would help members of the care team to identify issues for which mothers have not yet adequately prepared before discharge.

\section{RELEVANCE TO CLINICAL PRACTICE}

Access to reliable, valid and culturally appropriate instruments is crucial in describing the state of a mother's readiness for hospital discharge as well as for developing and evaluating nursing interventions for Iranian mothers with preterm infants hospitalised in NICU. The findings of this study inform clinicians, researchers and leaders on how the Persian version of the Parent Readiness for 
Hospital Discharge Scale of the need to integrate assessment of discharge readiness as a standard practice for discharge of mothers and infants from the NICU. The tool could be used to help nurses involved in direct clinical nursing practice to identify deficits in parental readiness for hospital discharge and provide a basis for identification of interventions to improve discharge readiness and refer to postdischarge follow-up services such as home visits in order to mitigate risks for postdischarge problems of both mothers and infants. In addition, the RHDS can be used in clinical nursing education to assist nursing students to learn how to thoroughly assess parents' needs in anticipation of discharge of a high-risk newborn from the NICU.

\section{CONFLICT OF INTEREST}

The authors report no conflicts of interest.

\section{AUTHOR CONTRIBUTIONS}

N.S. was responsible for conceptualisation and design of the study. N.S., M.Z.M. and S.K. were responsible for data acquisition and analysis. All authors participated in interpretation of the data, preparation of the manuscript and review of the final manuscript.

\section{REFERENCES}

American Academy of Pediatrics (AAP) Committee on Fetus and Newborn (2008). Hospital discharge of the highrisk newborn. Pediatrics, 122(5), 1119-1126.

American Academy of Pediatrics (AAP) Committee on Injury, Violence, and Poison Prevention (2011). Child passenger safety. Pediatrics, 127(4), 788- 793.

Anthony, M. K., \& Hudson-Barr, D. (2004). A patient-centered model of care for hospital discharge. Clinical Nursing Research, 13(2), 117- 136.

Arzani, A., Kermanshahi, S., Zahedpasha, Y., \& SalehMohamadzadeh, E. (2009). The role of predischarge mothers' education on follow-up examination of visual, hearing and brain problems in preterm neonates. Hormozgan Medical Journal, 13(2), 115- 122.

Beaton, D. E., Bombardier, C., Guillemin, F., \& Ferraz, M. B. (2000). Guidelines for the process of cross-cultural adaptation of self-report measures. Spine, 25(24), 3186-3191.

Bissell, G., \& Long, T. (2003). From the neonatal unit to home: How do parents adapt to life at home with their baby? Journal of Neonatal Nursing-London, 9, 7-13.

Bruder, M. B., \& Cole, M. (1991). Critical elements of transition from NICU to home and follow-up. Children's Health Care, 20(1), 40- 49.

Brunssen, S., \& Miles, M. (1996). Sources of environmental stress experienced by mothers of hospitalized medically fragile infants. Neonatal Network, 15(3), 88-89.

Bull, M. J., \& Engle, W. A. (2009). Safe transportation of preterm and low birth weight infants at hospital discharge. Pediatrics, 123(5), 1424- 1429.

Burnham, N., Feeley, N., \& Sherrard, K. (2013). Parents' perceptions regarding readiness for their infant's discharge from the NICU. Neonatal Network, 32(5), 324- 334.

Chen, Y., \& Bai, J. (2017). Reliability and validity of the Chinese version of the Readiness for Hospital Discharge Scale-parent form in parents of preterm infants. International Journal of Nursing Sciences, 4(2), 88-93. https://doi.org/10.1016/j.ijnss.2017.01.009

Coleman, E. A., Mahoney, E., \& Parry, C. (2005). Assessing the quality of preparation for posthospital care from the patient's perspective: The care transitions measure. Medical Care, 43(3), 246- 255. https://doi.org/10.1097/00005650-200503000-00007 
Declercq, E., Cunningham, D. K., Johnson, C., \& Sakala, C. (2008). Mothers' reports of postpartum pain associated with vaginal and cesarean deliveries: Results of a national survey. Birth, 35(1), 16-24. https://doi.org/10.1111/j.1523-536X.2007.00207.x

Desai, A. D., Jacob-Files, E. A., Lowry, S. J., Opel, D. J., Mangione-Smith, R., Britto, M. T., \& Howard, W. J.(2018). Development of a caregiver-reported experience measure for pediatric hospital-to-home transition. Health Services Research, 53(Suppl 1), 3084- 3106. https://doi.org/10.1111/1475$\underline{6773.12864}$

Discenza, D. (2009). NICU parents' top ten worries at discharge. Neonatal Network, 28(3), 202- 203. https://doi.org/10.1891/0730-0832.28.3.202

Epel, E. S., McEwen, B. S., \& Ickovics, J. R. (1998). Embodying psychological thriving: Physical thriving in response to stress. Journal of Social Issues, 54(2), 301-322. https://doi.org/10.1111/j.15404560.1998.tb01220.x

Franck, L. S., Oulton, K., Nderitu, S., Lim, M., Fang, S., \& Kaiser, A. (2011). Parent involvement in pain management for NICU infants: A randomized controlled trial. Pediatrics, 128(3), 510- 518. https://doi.org/10.1542/peds.2011-0272

Graumlich, J. F., Novotny, N. L., \& Aldag, J. C. (2008). Brief scale measuring patient preparedness for hospital discharge to home: Psychometric properties. Journal of Hospital Medicine, 3(6), 446- 454. https://doi.org/10.1002/jhm.316

Griffin, J. B., \& Pickler, R. H. (2011). Hospital-to-home transition of mothers of preterm infants. MCN: the American Journal of Maternal/Child Nursing, 36(4), 252- 257. https://doi.org/10.1097/NMC.0b013e31821770b8

Hamilton, B. E., Hoyert, D. L., Martin, J. A., Strobino, D. M., \& Guyer, B. (2013). Annual summary of vital statistics: 2010-2011. Pediatrics, 131(3), 548- 558. https://doi.org/10.1542/peds.2012-3769

Hynan, M., Mounts, K., \& Vanderbilt, D. (2013). Screening parents of high-risk infants for emotional distress: Rationale and recommendations. Journal of Perinatology, 33(10), 748- 753. https://doi.org/10.1038/ip.2013.72

Kelly, M. M. (2006). Primary care issues for the healthy premature infant. Journal of Pediatric Health Care, 20(5), 293- 299. https://doi.org/10.1016/i.pedhc.2006.01.002

Knapp, T. R., \& Brown, J. K. (1995). Ten measurement commandments that often should be broken. Research in Nursing \& Health, 18(5), 465-9.

Lamarche-Vadel, A., Blondel, B., Truffert, P., Burguet, A., Cambonie, G., Selton, D., ... Kaminski, M. (2004). Rehospitalization in infants younger than 29 weeks' gestation in the EPIPAGE cohort. Acta Paediatrica, 93(10), 1340-1345. https://doi.org/10.1111/j.1651-2227.2004.tb02934.x

Lian, Y. C., Ying, S. H. K., Peng, C. C., \& Yann, T. Y. (2008). Early discharge study for premature infants: Singapore general hospital. The Permanente Journal, 12(4), 15. https://doi.org/10.7812/TPP/08-040

MacCallum, R. C., \& Austin, J. T. (2000). Applications of structural equation modeling in psychological research. Annual Review of Psychology, 51(1), 201- 226. https://doi.org/10.1146/annurev.psych.51.1.201

Mackenzie, C. S., Smith, M. C., Hasher, L., Leach, L., \& Behl, P. (2007). Cognitive functioning under stress: Evidence from informal caregivers of palliative patients. Journal of Palliative Medicine, 10(3), 749-758. https://doi.org/10.1089/ipm.2006.0171

Mohammadbeigi, A., Mohammadsalehi, N., \& Aligol, M. (2015). Validity and reliability of the instruments and types of measurments in health applied researches. Journal of Rafsanjan University of Medical Sciences, 13(12), 1153-1170.

Ong, K. K., Preece, M. A., Emmett, P. M., Ahmed, M. L., \& Dunger, D. B. (2002). Size at birth and early childhood growth in relation to maternal smoking, parity and infant breast-feeding: Longitudinal birth cohort study and analysis. Pediatric Research, 52(6), 863-867. https://doi.org/10.1203/00006450-200212000$\underline{00009}$ 
Organization, W. H. (2016). Guideline daily iron supplementation in infants and children, Switzerland, CH: World Health Organization.

Polit, D. F., \& Beck, C. T. (2006). The content validity index: Are you sure you know what's being reported? Critique and recommendations. Research in Nursing \& Health, 29(5), 489-497. https://doi.org/10.1002/nur.20147

Polit, D. F., Beck, C. T., \& Owen, S. V. (2007). Is the CVI an acceptable indicator of content validity? Appraisal and recommendations. Research in Nursing \& Health, 30(4), 459- 467.

Raines, D. A. (2013a). Mothers' stressor as the day of discharge from the NICU approaches. Advances in Neonatal Care, 13(3), 181-187.

Raines, D. A. (2013b). Preparing for NICU discharge: Mothers' concerns. Neonatal Network, 32(6), 399- 403.

Richardson, D. K., Zupancic, J. A., Escobar, G. J., Ogino, M., Pursley, D. M., \& Mugford, M. (2001). A critical review of cost reduction in neonatal intensive care II. Strategies for reduction. Journal of Perinatology, 21(2), 121- 127.

Scherf, R., \& Reid, K. W. (2006). Going home: What NICU nurses need to know about home care. Neonatal Network, 25(6), 421-425.

Sharifi, N., Dolatian, M., Fathnezhad, A., Pakzad, R., Mahmoodi, Z., \& Nasrabadi, F. M. (2018). Prevalence of low birth weight in Iranian Newborns: A systematic review and metaanalysis. International Journal of Womens Health and Reproduction Sciences, 6(3), 233- 239.

Singer, L. T., Fulton, S., Kirchner, H. L., Eisengart, S., Lewis, B., Short, E., ... Baley, J. E. (2010). Longitudinal predictors of maternal stress and coping after very low-birth-weight birth. Archives of Pediatrics \& Adolescent Medicine, 164(6), 518- 524.

Smith, V., Hwang, S., Dukhovny, D., Young, S., \& Pursley, D. (2013). Neonatal intensive care unit discharge preparation, family readiness and infant outcomes: Connecting the dots. Journal of Perinatology, 33(6), 415-421.

Suderman, E. M., Deatrich, J. V., Johnson, L. S., \& Sawatzky-Dickson, D. M. (2000). Action research sets the stage to improve discharge preparation. Pediatric Nursing, 26(6), 571.

te Pas, A. B. (2017). Improving neonatal care with technology. Frontiers in Pediatrics, 5, 110.

Weiss, M., Johnson, N. L., Malin, S., Jerofke, T., Lang, C., \& Sherburne, E. (2008). Readiness for discharge in parents of hospitalized children. Journal of Pediatric Nursing, 23(4), 282- 295. https://doi.org/10.1016/i.pedn.2007.10.005

Weiss, M. E., Lerret, S. M., Sawin, K. J., \& Schiffman, R. F. (2020). Parent Readiness for Hospital Discharge Scale: Psychometrics and association with postdischarge outcomes. Journal of Pediatric Health Care, 34(1), 30-37. https://doi.org/10.1016/i.pedhc.2019.06.011

Weiss, M. E., \& Lokken, L. (2009). Predictors and outcomes of postpartum mothers' perceptions of readiness for discharge after birth. Journal of Obstetric, Gynecologic \& Neonatal Nursing, 38(4), 406- 417. https://doi.org/10.1111/j.1552-6909.2009.01040.x

Weiss, M. E., \& Piacentine, L. B. (2006). Psychometric properties of the readiness for hospital discharge scale. Journal of Nursing Measurement, 14(3), 163-180. https://doi.org/10.1891/jnm-v14i3a002

Weiss, M. E., Sawin, K. J., Gralton, K., Johnson, N., Klingbeil, C., Lerret, S., ... Schiffman, R. (2017). Discharge teaching, readiness for discharge, and post-discharge outcomes in parents of hospitalized children. Journal of Pediatric Nursing, 34, 58- 64. https://doi.org/10.1016/i.pedn.2016.12.021

Wereszczak, J., Miles, M. S., \& Holditch-Davis, D. (1997). Maternal recall of the neonatal intensive care unit. Neonatal Network: NN, 16(4), 33-40.

Williams, B., Onsman, A., \& Brown, T. (2010). Exploratory factor analysis: A five-step guide for novices. Australasian Journal of Paramedicine, 8(3). https://doi.org/10.33151/ajp.8.3.93

Zarbock, S. F. (1998). Hospital discharge of the high-risk neonate. Home Care Provider, 3(6), 302-303. https://doi.org/10.1016/S1084-628X(98)90006-5 